\title{
Movimientos religiosos y privaciones materiales
}

\author{
Maximiliano Korstanje
}

PABLO SEMÁN, 2000

\section{"El pentecostalismo y la religiosidad de los sectores populares"}

en Maristella Suampa, Desde abajo, Biblos, Buenos Aires, pp. 155-180.

MARÍA JULIA CAROZZI, 1993

\section{"Tendencias en el estudio de los nuevos movimientos religiosos"}

Sociedad y Religión, vol. 10, núm. 11, pp. 3-23.

ALEJANDRO FRIGERIO, 1999

\section{"El futuro de las religiones mágicas en Latinoamérica"}

Ciencias Sociales y Religión, año 1, núm. 1, pp. 51-88.

\section{Religious Movements and Material Deprivations}

MaXimiliano KORSTANJE: Universidad de Palermo, Argentina. maxikorstanje@hotmail.com

Desacatos, núm. 28, septiembre-diciembre 2008, pp. 203-206.
$\mathrm{L}$ a siguiente reseña versa sobre tres artículos relacionados con los nuevos movimientos religiosos en Argentina y las privaciones materiales que supone "la pobreza".

El primer artículo, de Pablo Semán, titulado "El pentecostalismo y la religiosidad de los sectores populares", hace referencia a la religiosidad popular de Emilia, quien perdió a su marido a causa del alcoholismo. Aún sin ser evangélica, Emilia ofreció a su marido (antes de morir éste) asistir a un grupo evangélico como modo de curación de su enfermedad. En este sentido, Semán sostiene "los evangelios son, para Emilia, una variación probablemente más interesante y efectiva de alternativas religiosas, culturales y terapéuticas que forman parte de su universo cotidiano" (p. 156).

Villa L, donde vive Emilia, es un barrio configurado en el segundo cordón industrial del Gran Buenos Aires. Conviven allí familias provenientes de clases medias bajas y bajas con familias de inmigrantes limítrofes. En Argentina, si bien entre 70 y $75 \%$ de su 


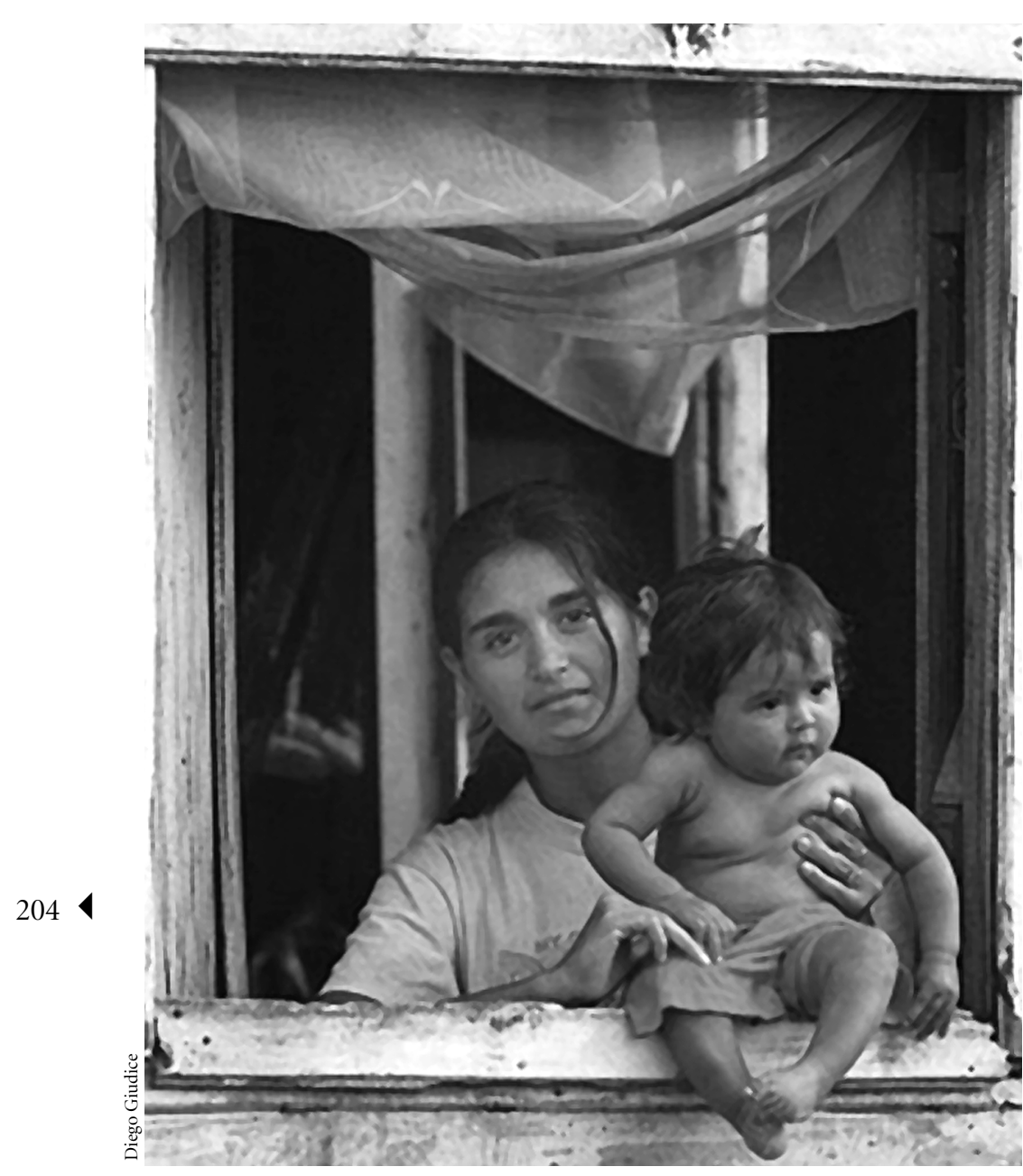

San Miguel de Tucumán, Argentina.

población se define como católica, el pentecostalismo aúna en sus filas aproximadamente a 20\% del total de la población. Semán cuestiona lo que el paradigma católico construirá a partir de la construcción del mundo cotidiano de Emilia y su vínculo con la religiosidad.

El pentecostalismo ofrece (entre otras cosas) la posibilidad de que la divinidad intervenga directamente en la vida de los fieles. La hipótesis inicial del autor lleva a suponer que los estados de privación en ciertos sectores y contexto persiguen ofertas religiosas específicas. En otros términos: "el crecimiento del pentecostalismo puede explicarse por la capacidad que tienen estos grupos de movilizar y combinar los supuestos culturales pre-existentes de los grupos afectados por diversas formas de pobreza" (p. 158).

Este último punto es retomado también por María Julia Carozzi, quien en su trabajo llamado "Tendencias en el estudio de los nuevos movimientos religiosos en América" se propone realizar una revisión sintética de los hallazgos teóricos y metodológicos realizados bajo la redefinición conceptual de Iglesia y secta, los procesos de conversión religiosa y la relación entre el surgimiento de los nuevos movimientos con la pobreza. A diferencia de Semán, el abordaje de Carozzi es puramente teórico. En la primera parte de su trabajo, la autora explica el cambio acaecido por parte de un gran número de investigadores respecto al estudio de las sectas, como elemento analítico, en contraposición con la Iglesia.

A partir de la década de 1960 se propuso la idea de que tanto secta como Iglesia sean clasificaciones aplicables a cualquier grupo religioso en relación con el grado de tensión existente entre el grupo y el ambiente sociocultural. De esta forma, las Iglesias se convertían en cuerpos "homogéneos" con un escaso nivel de tensión mientras que las sectas (derivadas de los cismas) encarnaban una elevada tensión inter e intragrupal (p. 5).

Obviamente, años después ciertos elementos empíricos cuestionaron este supuesto. En efecto, no todos los grupos eclesiásticos demuestran equilibrio institucional, como tampoco todas las sectas adquieren posturas hostiles en las comunidades en las que se encuentran insertas.

Con respecto a su sistema de conversión, Carozzi explica que el surgimiento de los estudios focalizados en el tema de la conversión obedece a dos factores principales: la influencia de 
los medios masivos de comunicación por un supuesto "lavado de cerebro" para provocar una conversión forzada y la persistencia en suponer que la secularización impone a la gente nuevas formas de "idolatría".

Finalmente, el tratamiento de Carozzi con respecto a la pobreza apunta al hecho de que el surgimiento de ciertos movimientos religiosos reafirmarían la autoestima del "pobre". La abstención de ciertas riquezas materiales como símbolo de "humildad" espiritual garantizaría en el "otro mundo" un mejor pasar (p. 15). En este caso, se da una inversión en cuanto a la valoración similar a la postura weberiana sobre el surgimiento del cristianismo ${ }^{1}$.

$\mathrm{Al}$ respecto, Carozzi enfatiza que "los estudios sobre nuevos movimientos religiosos en América Latina ponen de manifiesto cómo los nuevos movimientos religiosos constituyen a menudo estrategias de supervivencia en familias pobres, proporcionando medios mágicos para el acceso a mayores recursos en momentos en que la movilización política pierde vigencia [...]. El hecho de que sean los pobres quienes mayoritariamente adhieran a estos movimientos, no parece implicar necesariamente que la pobreza y las estrategias para sobrevivir en ella sean la causa universal de su florecimiento" (p. 19).

Acorde con lo expuesto, la autora hace un llamamiento a la contrastación de las teorías contra estudios de campo empíricos que relacionen va-

\footnotetext{
${ }^{1}$ Max Weber, Sociología de la religión, Pléyade, Buenos Aires, 1978.
}

riables socioeconómicas con arreglo a la pobreza y la afiliación religiosa.

El último de los abordajes corresponde al profesor Alejandro Frigerio en su artículo titulado "El futuro de las religiones mágicas en Latinoamérica". El autor reflexiona sobre el componente mágico dentro de los nuevos movimientos religiosos latinoamericanos, utilizando como marco teórico la propuesta estadounidense de Stark y Bainbridge de los compensadores específicos ${ }^{2}$.

Frigerio argumenta que, en primera instancia, los grupos religiosos tienen una importante oferta de servicios mágicos como respuesta a las privaciones cotidianas; segundo, que ese encuentro entre oferta y demanda evoluciona temporalmente en concordancia con el juego de los "actores" que intervienen. Más específicamente, los diferentes movimientos (oferta) trabajan las etapas de acercamiento con los potenciales fieles por medio del diagnóstico, en el cual sobresaltan atribuciones de culpabilidad, soluciones para el problema planteado y vocabularios de motivos para explicar y justificar las circunstancias contextuales que lo han llevado a la situación en la que vive (p. 53).

Frigerio supone que la teoría sobre los compensadores específicos explica la creación y posterior mantenimiento del vínculo entre el fiel y su comunidad religiosa. La idea central de este marco es que "los hombres buscan lo que perciben que son recompensas, $y$

\footnotetext{
2 Rodney Stark y William Bainbridge, The Future of Religion, University of California
} Press, Berkeley, 1985. evitan lo que perciben que son costos" (p. 54). Estas recompensas, en ocasiones y por diversos aspectos, no pueden ser alcanzadas. Surgen, entonces, ciertos compensadores (creencias) que justifican esa limitación (por lo general en un futuro). Explica Frigerio: "la noción de compensador es la clave para su teoría de la religión, y se halla en la base de su distinción entre magia y religión" (p. 54). Dependiendo de la posición que tomen los compensadores, éstos pueden ir desde lo general (abstracto) hacia lo específico (concreto). En otras palabras, la promesa de una mejor vida en el otro mundo se convierte en un compensador general, mientras que la adquisición de un mejor sueldo en el trabajo se refiere a un compensador específico.

Con ciertas discrepancias con respecto a Stark y Bainbridge, Frigerio señala (correctamente) que no necesariamente las ofertas de magia y religión deben ser concebidas en forma separada en la relación fiel/creencia, como tampoco que los compensadores específicos sean de fácil refutación (como presuponen Stark y Bainbridge). Aún dentro de la magia existen diversos mecanismos que poseen dinámicas autovalidantes con respecto al mundo cotidiano de las negociaciones que de él se derivan. Esta observación, sostiene Frigerio, se apoya en su experiencia de campo con practicantes de Umbanda a lo largo de seis años en la ciudad de Buenos Aires.

Las estadísticas sugieren que la transitoriedad por la cual pasan las personas que van a un templo umbanda es alta. De 150 consultados, 75\% había asistido al mismo templo durante un 
año, $52 \%$ por menos de seis meses, $y$ casi un tercio menos de un mes. El autor esboza aquí una relación analítica-conceptual muy interesante: cuando los compensadores específicos no son cumplidos en forma recurrente desvinculan al fiel de su comunidad. En esta etapa impera el elemento mágico que, sin embargo, se convierte en religioso en el momento en que el fiel pasa de ser un mero receptor de los favores "divinos" a un intermediario o proveedor de compensadores específicos.

Aunque Frigerio no lo mencione expresamente, este proceso comprende dos etapas bien distintas: una de recepción de los favores divinos y otra de conversión o devoción del fiel con respecto a esa divinidad. En el caso de Umbanda, esto explicaría que muchos fieles pasen de templo en templo, empero, sin cambiar de afiliación religiosa. El autor sostiene (entonces): "obviamente estoy brindando una versión algo simplificada de un proceso complejo, y variante en cada caso. Sin embargo, una de las constantes en la vida de los umbandistas/batuqueros que observé a lo largo de muchos años de trabajo de campo es la relación entre sus problemas cotidianos y la promesa de resolución mediante iniciaciones con la dinámica de sus carreras religiosas" (p. 66).

En el caso del pentecostalismo la oferta de compensadores específicos cumple un papel muy similar al ya descrito. El énfasis de esta clase de movimiento se centra en un mejoramiento en esta vida (compensador específico). Esto, si bien resulta atractivo para ciertos sectores de la socie- dad que recién se inician, para los miembros ya activos la tendencia es avocarse a la santificación (compensador general) (p. 68).

En el caso de la Iglesia del Pasto Giménez, "los temas enfatizados en los mensajes dirigidos a los inconversos son algo diferentes a los que el pastor dirige a quienes ya se han convertido" (p. 69). Así, "se establece un nuevo acuerdo [...] entre el individuo, Jesús y su Iglesia. Apelando a este nuevo pacto, el individuo reconoce que no recibió las bendiciones por su culpa, aumenta su compromiso con el grupo religioso y se pone en marcha un nuevo ciclo de ofrecimiento de compensadores específicos" (p. 71). En este sentido (y en similitud con Carozzi), el trabajo de Frigerio apunta a probar que los individuos se presentan ante las diferentes religiones con demandas insatisfechas. Estas demandas obedecen a problemas puntuales que deben ser solucionados (compensadores específicos). Luego, una vez solucionados, los fieles deben contribuir "a construir el efecto mágico" por medio de diversos mecanismos como son la devoción, la santificación o la abnegación personal a la "causa" (p. 77).

Puntualmente, el aporte del profesor Frigerio no sólo se aplica para los movimientos religiosos, sino también para ciertos aspectos más generales, como los movimientos nacionalistas, en los cuales la autoridad esté legitimada por un orden carismático ${ }^{3}$.

${ }^{3}$ Weber, op. cit:; Meredith Mcguire, "Defining Religión”, en Religión: The Social Context, Wadsworth, Washington, 1997, pp. 8-20; Norbert Elías, La civilización de los padres y otros
Movidos por limitaciones materiales que pueden haber sido provocadas por crisis económico-financieras o derrumbamiento de instituciones políticas, los nacionalismos han actuado como compensadores específicos durante un lapso temporal. Una vez concretados sus objetivos, han contribuido a conformar un orden sagrado (mítico) que exacerba ciertos elementos culturales (etnocentrismo) con respecto a otros pueblos. La devoción que exige este tipo de causas "nacionales" se convierte en compensador general y, de esta forma, el problema de doña Emilia, puntual y específico, pasa a convertirse, una vez resuelto, en una "causa nacional" santificada por una identidad endo-grupal muy elevada y en ocasiones impermeable ${ }^{4}$.

"El poder político nunca está completamente desacralizado en las sociedades", argumentaba George Balandier preocupado por el tema. En efecto, continuaba, "y en el caso de las sociedades denominadas tradicionales, la relación con lo sagrado se impone con cierta evidencia. Discreto o aparente, lo sagrado está siempre presente en el interior del poder"s.

Noviembre 2007

ensayos, Norma, Bogotá, 1998; Mathew Evans, "The Sacred: Differentiating, Clarifying and Extending Concepts", Review of Religious Research, vol. 45, núm. 1, Young University, Brigham, 2003, pp. 32-47; George Balandier, Antropología política, Ediciones del Sol, Buenos Aires, 2004; Clifford Geertz, La interpretación de las culturas, Gedisa,

Buenos Aires, 2005.

${ }^{4}$ Mircea Eliade, Mito y realidad, Guadarrama, Madrid, 1968.

${ }^{5}$ Balandier, op. cit. 